\title{
北京大学分析化学系列小班阅读讨论课的教学实践
}

李娜 ${ }^{*}$ 李美仙, 王申林, 刘小云, 白玉, 朱志伟

北京大学化学与分子工程学院, 北京 100871

摘要: 简介了北京大学化学与分子工程学院分析化学系列基础课(定量分析化学、仪器分析、中级分析化学)开展小 班阅读讨论课教学的实践。

关键词: 分析化学系列课程; 小班阅读讨论课

中图分类号: G64; O6

\section{Practice of Analytical Chemistry Group Discussion Class Series at Peking University}

$\mathrm{Na} \mathrm{Li}{ }^{*}$, Meixian Li, Shenlin Wang, Xiaoyun Liu, Yu Bai, Zhiwei Zhu

College of Chemistry and Molecular Engineering, Peking University, Beijing 100871, P. R. China.

Abstract: The practice of Analytical Chemistry Group Discussion Class (ACGDC) series at College of Chemistry and Molecular Engineering, Peking University is briefly introduced.

Key Words: Analytical chemistry course series; Small-class seminar

分析化学是发展和应用各种方法、仪器和策略, 以获得有关物质在空间和时间方面组成和性质 的信息的学科 ${ }^{[1]}$ 。2018 年度国家自然科学基金委员会化学科学部进行学科调整, 按照化学主要研究 方向进行资助。其中, 化学测量学旨在发展化学相关的测量策略、原理、方法与技术, 研制各类分 析仪器、装置及相关软件, 以精准获取物质组成、分布、结构与性质的时空变化规律 ${ }^{[2]}$ 。可以看出分 析化学是化学测量学方向的主要内容, 而化学测量学则为各个研究领域提供支撑。因此, 在培养拔 尖/引领人才的创新性思维、学术能力与综合素质中, 学习和掌握分析化学原理和方法、并熟练应用 于实际问题的解决, 是一个必要的前提基础。当今, 由于社会信息爆炸、IT 技术急速发展, 并不断 涌现新的分析化学测量原理与方法, 使得不仅不可能在课程中将所有的分析技术一一讲授或学习, 而且知识传授的必要性也越来越小, 更重要的是要摸索新的教学形式, 培养学生主动学习的能力, 传授分析化学学科思路和解决问题策略, 做到真正 “授之以渔”。针对学生中拔尖人才培养, “小班 教学” 是最适合的教学方式之一, 也是实现将本科基础教育与未来的研究生专业教育无缝对接的一 个可行策略 ${ }^{[3,4,5-10]}$ 。

\section{1 分析化学系列课程小班教学基本情况}

讲授基础课的教员大约十年前就针对前 5\%-10\%的学生如何开展教学进行过讨论, 即如何使这 些学生能够在大学基础课的学习阶段获得更好的培养, 以在未来的学术领域中具有潜在的学术引领 
能力。2016 年春季学期起, 北京大学化学与分子工程学院针对分析化学系列理论课程(定量分析化 学、仪器分析、中级分析化学)全面开设与大班授课平行的阅读讨论小班课, 希望通过阅读与讨论来 培养学生的学术鉴赏能力、创新性思维、综合素质, 以及沟通技能与团队合作精神 ${ }^{[11]}$ 。这 3 门系列 课程, 共 96 学时, 每周课堂时间为 3-4 学时, 开课时间为第二、三学期。开课人数限制在 15 人以 内, 采用自愿报名与考试篮选相结合, 录取小班课学生。小班课程仍然执行目前 3 门课的教学大纲 中的内容, 因材施教、适度提高教学要求。采用讲授、指定阅读和课堂讨论相结合的模式进行教学, 课堂讨论的内容包括自学原理、方法解析、学科进展和应用案例等内容(表 1)。考核以过程性评价为 主，分数由课堂讨论表现、作业、读书报告与测验四部分组成。

\section{2 教学内容与教学方法}

讲授 “分析化学学科思路和解决问题策略” , 是我们一直为之努力的教学理念。对阅读讨论小 班课的教学方式(例如研讨、讲授、专题讨论以及问题导向学习等)进行合理设计与使用, 在现今知识 爆炸、不断涌现新的分析化学原理与方法的时代, 希望从根本上帮助学生抓住分析方法的精髓, 从 知识、能力和素质多方面培养学生的创造性思维以及创新能力。为此在以下几个方面进行了尝试: 教师讲授与课堂讨论结合, 合理地分配讲授/阅读/讨论内容; 选择讨论专题、引入与积累新的教学实 例与案例, 达到教学内容的与时俱进; 合理设置考查方法, 全面和真实地反映学生的能力及成长。 分析化学阅读小班课教学是贯穿在整个分析化学基础课教学中的小班教学, 使学生在受到系统扎实 的基础训练的同时，获得综合能力的培养和提升。

表 1 教学内容、教学形式与学时分配

\begin{tabular}{|c|c|c|}
\hline 教学内容 & 教学形式 & 学时 \\
\hline 分析化学概述与方法思路、容量滴定分析 & 讲授 & $1+2$ \\
\hline 数据处理与分析 & 讲授 & 6 \\
\hline 仪器分析概述、光谱分析测量基础、光学显微镜 & 讲授 & 6 \\
\hline 原子光谱分析: 原子吸收与发射光谱、X 射线吸收与苂光光谱 & 课堂讨论 & 7 \\
\hline $\begin{array}{l}\text { 分子光谱分析：分子光谱-紫外可见吸收光谱、红外光谱与拉曼光谱(包括表面增强拉曼光谱)、苂光光谱 } \\
\text { (包括菼光基础、溶剂影响、苂光猝灭、苂光共振能量转移、苂光寿命测量、化学与生物发光) }\end{array}$ & 课堂讨论 & 20 \\
\hline 表面分析简介、流动注射、微流控分析简介、单分子检测简介 & 讲授 & 3 \\
\hline 电分析: 引论、电位分析法、电解和库仑分析法、极谱法和伏安法、其他电分析方法 & 课堂讨论 & 9 \\
\hline $\begin{array}{l}\text { 核磁共振波谱分析：基本原理、核磁共振波谱仪、自旋-自旋耦合、核 Overhauser 效应(NOE)、 } \\
\text { 二维核磁简介 }\end{array}$ & 课堂讨论 & 12 \\
\hline 色谱分析讨论: 色谱法原理、气相色谱法、高效液相色谱法 & 课堂讨论 & 3 \\
\hline 质谱分析法: 基本原理、质谱仪、串联质谱、色谱-质谱联用 & 课堂讨论 & 6 \\
\hline 单分子研究 & 课堂讨论 & 12 \\
\hline 5 次测验: 定量化学分析; 光谱分析 1 ; 光谱分析 2 ; 电分析; 核磁共振波谱分析、色谱分析、质谱分析 & & 10 \\
\hline
\end{tabular}

课堂讲授与讨论内容: 1) 由于选修小班课的学生基本上是国家级化学竞赛金牌或银牌得主, 对 化学分析的部分相对较熟悉, 通过选拔考试进一步了解其对该部分内容掌握的程度以及存在的问题, 因此容量分析部分内容主要针对存在的问题进行重点讲解。2) 分析化学课程涉猎的基础知识面深而 广, 除了物理化学, 还涉及数理统计、电磁学、光学以及统计热力学。结合选拔和调查反映出的共 性问题与需求, 对准备知识、解决分析化学问题基本思路、数据处理以及化学分析方法的关键问题 进行适当的讲授。重点加强数据处理和结果分析的训练。对于分析化学中的数据表达、处理与分析 
则相对增加学时, 除了常规的 $t$ 检验方法, 还讲授配对样本 $t$ 检验; 除了对数据精密度的 $F$ 检验, 还增加方差分析简介; 增加线性拟合内容以及在分析化学中的应用, 在每一次测验中都有线性拟合 方法相关的题目, 以加深学生对获得分析结果的统计学处理方法的理解, 提高其应用能力。3) 课程 的最后一部分 (12 学时), 将讨论主题与读书报告主题由多个主题调整为 “单分子检测” 主题, 带领 学生阅读 Nobel Symposium Lecture 系列丛书《Single Molecule Detection》, 请学生进行课堂报告与 讨论, 学习与领略国际最顶尖的单分子研究科学家的工作与研究思路, 所有的学生都以极大的兴趣 投入, 并且都表示这部分的讨论收获很大。

课堂讨论: 在学生掌握普适原理的基础上, 对于各种仪器分析方法, 以及中级分析化学中的内 容, 由学生主导课堂讨论, 讲解基本原理与应用, 并负责组织讨论与回答问题。每位学生分别主导 一次基础内容和一次应用讨论, 基础部分要求原理讲述清楚, 包括定性与定量分析的原理, 仪器哪 些部分影响定性与定量分析等, 应用部分则要求讲明白方法的具体原理与涉猎的基础知识、方法亮 点与适用范围, 以及可能存在的问题。每一位学生的讲解时间为 40 分钟, PPT 建议限制在 20-25 页 以内, 要设计问题提问。提前一周开讨论小组会, 教师与学生一起审查课件, 确保讨论内容全面合 理, PPT 简明扼要。

阅读文献、撰写读书报告: 读书报告是过程评价的重要内容之一。针对教学内容选择基础与前 沿相结合的相关文献, 供学生阅读, 并撰写读书报告, 每学期至少提交 5 篇读书报告。要求针对一 篇论文的摘要进行翻译, 对全文原理、重要结果与结论、亮点进行概括, 并提出自己的看法。学生 们通过阅读文献、撰写读书报告这个环节, 可以检验所学的知识, 并且拓展学习内容, 锻炼思考、 质疑能力以及对文献所涉及课题的鉴赏能力。

过程评价与阶段性测验相结合的考查方法：除了课堂讨论、作业, 以及读书报告等过程评价, 为保证学生掌握扎实的基本原理与基础知识, 配有阶段性测验, 并要求学生进行阶段学习要点总结, 在测验当场提交总结。

为确保阅读讨论小班课教学的顺利进行, 教学团队由具有 20 多年教学经验、取得了优秀教学成 就并具备了较高学术水平的老教师以及具有较高学术造诣的优秀青年教师组成。这些教师的学术专 长涵盖了课程的绝大部分内容, 能够在讨论课中给学生以高屋建瓴的指导, 将科学最新进展渗透在 讨论中, 激励学生的创新能力与学术思维。同时, 聘用高年级本科生担任助教, 方便师生沟通。以 上举措确保了教学实践的顺利进行。

\section{3 结语}

分析化学系列课程的小班阅读研讨课是教师为主的讲授、学生主导的研讨, 以及问题导向学习 等教学方法的综合运用。讲授与讨论相结合, 除了培养学生的学习能力之外, 还能够培养学生的思 辨能力、表达能力、学术鉴赏力和批判性思维。阅读文献、撰写读书报告能够加强学生对原理的理 解, 培养学生抓住重点、提炼思想、综合写作与表达能力以及学术洞察力。针对不同教学内容与课 程, 有的放矢地采用特定的教学方法, 使教学效果最大化, 为培养拔尖人才的目标服务。分析化学 系列基础课程的阅读讨论小班教学, 不仅为分析化学教学法的研究积累经验, 也将为进一步进行因 材施教，培养有创新性思维人才提供依据。

\section{参 考 文 献}

[1] 李克安. 分析化学教程. 北京: 北京大学出版社, 2005: 3 .

[2] 化学科学四处资助范围—B04 化学测量学. (2013-12-01) [2019-07-16]. http://chem.nsfc.gov.cn/Show.aspx?AI=718.

[3] 俞汝勤, 梁逸曾. 大学化学, 2000, 15 (1), 1 .

[4] 俞汝勤. 大学化学, 2008, 23 (5), 1. 
[5] Zhang, S. C.; Zhang, X. R. Anal. Bioanal. Chem. 2014, 406, 4005.

[6] 郭祥群. 大学化学, 1999, 14 (4), 17.

[7] 郭祥群. 大学化学, 2008, 23 (5), 7.

[8] 金钦汉. 大学化学, 2003, 18 (1), 12.

[9] 王秋泉. 大学化学, 2002, 17 (5), 57.

[10] 郭祥群. 大学化学, 2016, 31 (3), 11.

[11] Dennick, K. E. R. Small Group Teaching: Tutorials, Seminars and Beyond; Routledge Falmer in Taylor \& Francis Group: London, 2004 ; p. 4. 